\title{
Preliminary Evaluation of Temperature Performance Using Empirical Eco-Friendly Approach in Reducing Energy Consumption
}

\author{
Wahidah Hashim ${ }^{1}$, Amirul Haziq Ahmad ${ }^{1}$, Ahmad Fadzil Ismail ${ }^{2}$, Kok-Lim \\ Alvin Yau ${ }^{3}$, Mohamed Kamrul Hasan ${ }^{2}$ and Noor Azlin Yahya ${ }^{4}$ \\ ${ }^{1}$ College of Science Computer \& Info Tech, Universiti Tenaga Nasional, \\ Malaysia \\ ${ }^{2}$ Faculty of Engineering, International Islamic University Malaysia, Malaysia \\ ${ }^{3}$ Dept of Computing and Information Systems, Sunway University, Selangor, \\ Malaysia \\ ${ }^{4}$ Forest Research Institute of Malaysia, Kepong, Malaysia \\ wahidah@uniten.edu.my,amirulhaziq18@gmail.com,
}

\begin{abstract}
The aim of this research is to quantify the percentage (\%) of reduction for indoor temperature by emulating a modelled house surrounded by plant in comparison to an identical model without any encircled plants. The motivation behind this study is to identify possible ecological means of passive cooling. It is a fact that there is a huge increase of air-conditioning cooling system usage by consumers in order to keep the temperature down. Air-conditioner can emit over a half billion ton of carbon dioxide into atmosphere, thus causing global warming to the earth. In our research, we hypothesize that, the trees manage to reduce the indoor temperature of a house through the evaporation process and shading. The studies measure the temperature reading using a programmable microprocessor acting as the temperature sensor. The result of this research shows that there was a temperature decrease in the range of 0.53 degree Celsius in comparison to the house without the surrounding plants. The experiment was conducted at an open space to ensure there was no effect of other trees except the one meant for the study. This finding perhaps can assist the government to start promoting the awareness of reducing carbon footprint by an eco-friendly technique to reduce indoor temperature with less cost on energy consumption.
\end{abstract}

Keywords: Climate change, eco-friendly technique, natural cooling technique, energy conservation, temperature sensor

\section{Introduction}

In Malaysia, according to the national census, about $85 \%$ of the existing houses in urban areas are made of brick than wooden materials which are undoubtedly warmer. These brick modern houses basically require air-conditioning to cope with the local tropical climate unlike the traditional wooden houses. In fact, the result of national census (Malaysia, 2000) showed that the total number of households with airconditioning in Malaysia has dramatically increased from 1300 in $1970(0.8 \%)$ to 229,000 in 1990 (6.5\%) and 775,000 in 2000 (16.2\%) [5].

Malaysia is an equatorial climate country where most of the time the humidity is usually low and temperature is hot throughout the years. The daytime temperature rises above 30 degree celcius ( 89 degree Fahrenheit) that contributes the reason why most Malaysians require air-conditioner most of the time, especially during prolonged drought which leads to higher operating cost and energy consumption. 
The issues rise when almost all the time the air-conditioners need to be switched on in order to keep the house or room cooler. The difference of yearly energy consumption between the household with air-conditioners and those without them is shown in Figure 1. The average yearly household energy consumption for the respondents with air-conditioners is 1.4 times higher than that for without airconditioners residents. This result proves that the reduction of air-conditioning usage might be one of effective ways to solve high energy consumption issues in urban Malaysians houses [1].

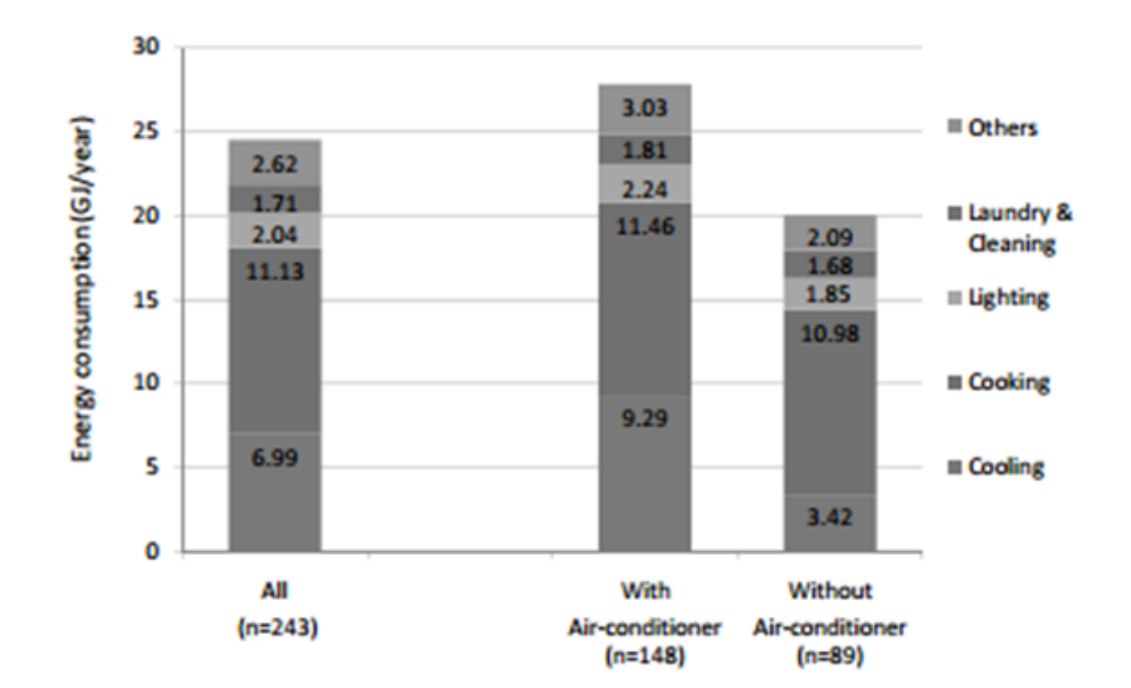

Figure 1. Energy Consumption with or without Air-Conditioner

According to the research conducted by US Forestry Commission, surface temperature within a green space can be 15-20 degree Celsius lower than that of the surrounding urban area, giving rise to 2-8 degree Celsius cooler air temperature whereby the cooling effect can extends out into the surrounding area [2]. Their research further explains that, the neighbourhoods with mature canopies indicated daytime air temperature 1.7-3.3 degree Celsius lower then were without trees. Their findings also show that by placing plants closely to the building and shading the wall directly, the surface temperature can decrease to 17 degree Celsius. However at noon, the indoor air temperature increases by 0.5 degree Celsius and indirectly effect the increment of air-conditioning cost by $25 \%-80 \%$.[2]

In addition to that, it was reported from the US Environmental Protection Agency (EAP) that the tree and vegetation impact to the surrounding can be estimated to reduce 20-45 degree Fahrenheit (11-25 degree Celsius) of temperature in comparison to the peak temperature of non-shaded surrounding [10]. In [3], the research shows under tree shading a value of 5 degree Celsius was the reading obtained for in-building air temperature. Almost similar result was also captured by a study in Malaysia with the decremented of 4 degree Celsius lower than the air temperature for exposed spaces [3].

From all these evidences, they indicate that cities frequently demonstrate higher means of average temperature compare to the surrounding rural area, which is known as heat island effect. However, the research is insufficient to prove the accurate temperature reduction for 2016 current climate for houses in urban places of Malaysia since previous studies were conducted back in 1995 . Hence, our preliminary objective of this study is to investigate the actual temperature reduction influenced by surrounded trees for the case of single sample house model. We have conducted an empirical research to find out the temperature differences through monitoring data using sensor device for further analyses. 
The rest of the paper is organized as follows. Section 2 describes, in brief, the methodology used to conduct the experiment. Section 3 covers our proposed temperature sensor system and required parameters. Section 4 discusses our experimental set-up for measuring the temperature behavior. Experimental results and discussion are discussed in Section 5. Finally, concluding remarks are highlighted in Section 6.

\section{Modelling the Temperature Monitoring System Architecture}

Figure 2 illustrates the system architecture of our studies in monitoring the impact of trees to the indoor temperature of a house. The idea of this model is improvised based on the Andrew Back's plant monitoring environment project.

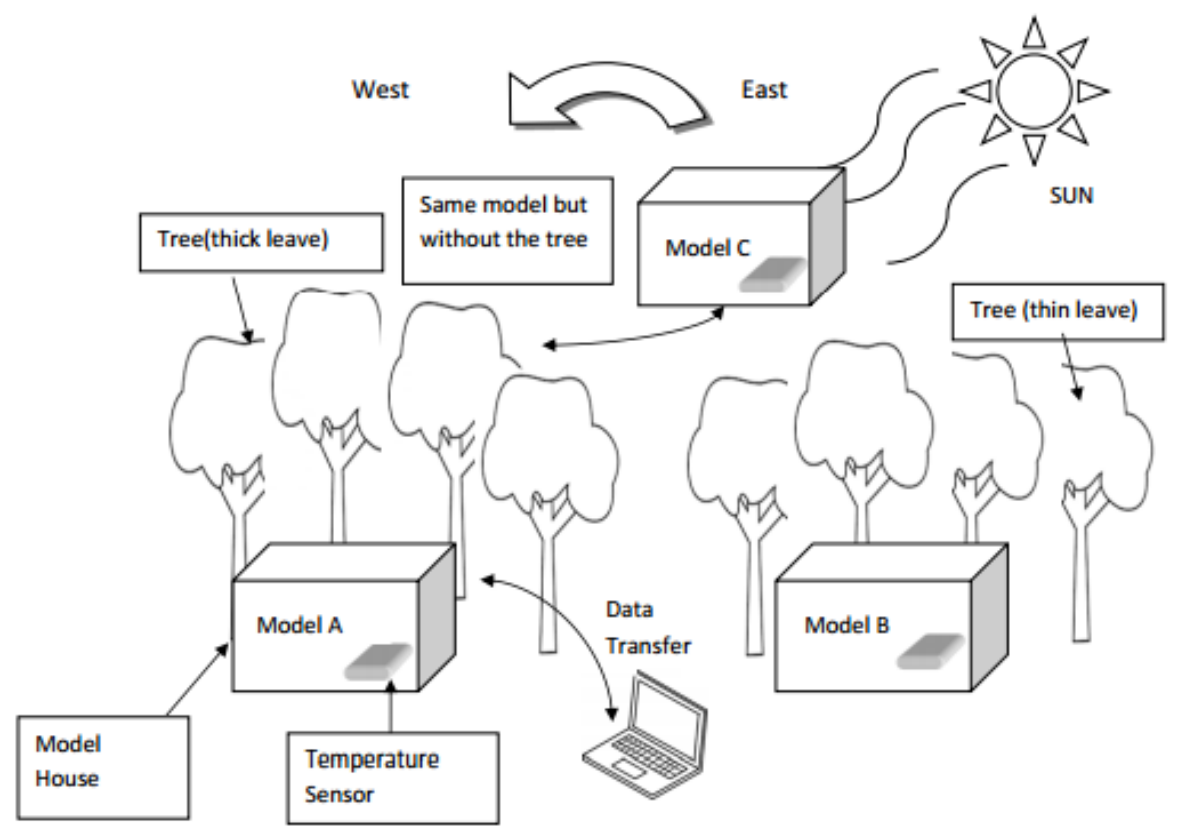

\section{Figure 2. System Architecture for Modelling the Temperature Monitoring Studies}

Model A and B each represents the wooden house model surrounded by two type of trees; the thick leaves and the thin leaves trees while model $\mathrm{C}$ represents the house without surrounded trees. In this house, a temperature sensor will be kept to measure indoor temperature and humidity of the house. For model A and B, both will be placed near certain type of plants as substitution to the actual tree representation. The houses will be exposed to daylights from 8.00 A.M until 4.30 P.M.

\subsection{Trees}

There are many type of trees in Malaysia that can be used as subjects under studies, however our main priority is to find for small or medium size tree with thick and thin shrubs. Besides that, the tree must also be taller than the house model. One of the main reason, the thick, tall and more shrubs type of tree provides wider shading and higher cooling effect. Location of the tree will be at the right and left side of the house, assuming the model house have been placed parallel to sun rise and down from the east and west. Common tree types that were used in our studies are selected as Garcinia Subelliptica and (Happy Tree) and Tabernaemontana corymbosa (Flore Pleno). Figure 3 shows the image of these plants, respectively. 

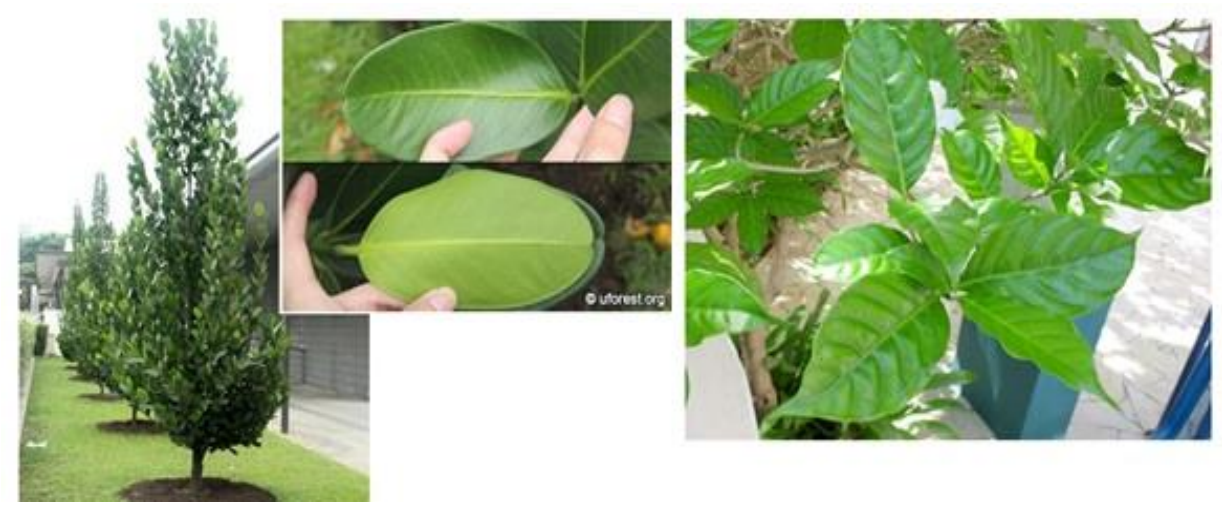

Figure 3. Garcinia Subelliptica (left, centre) and Tabernaemontana Corymbosa (right)
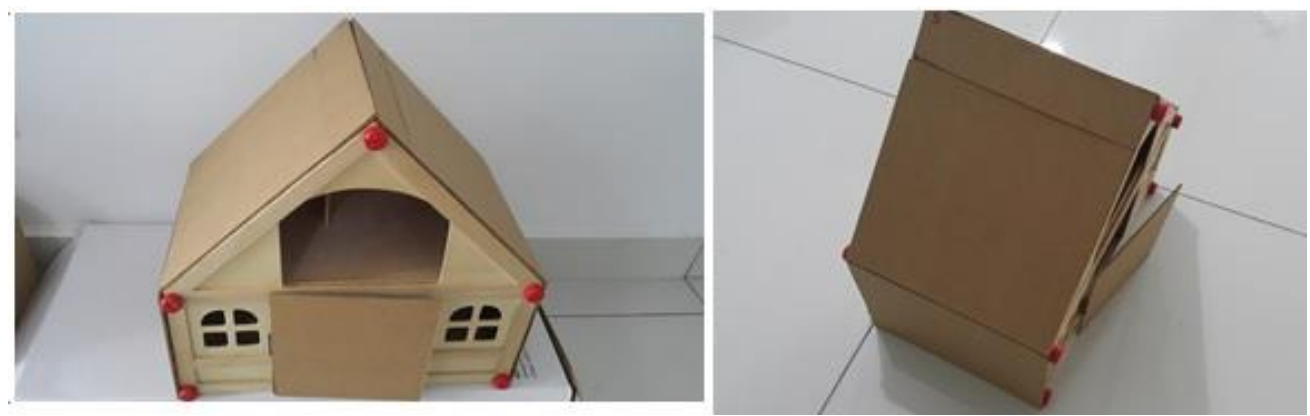

Figure 4. Front (left) and Top of the House Model (right)

Figure 4 on the other hands show the sample house model used in this research project. The house has been modified from wooden doll house all openings are closed to reduce any outside influence to the reading. There are 3 house model used in the studies and all have the same shape and material. Due to the limitation of cost, we only settled for a cardboard house model hence that limits our scope of monitoring to only non-rainy days.

\section{Proposed Temperature Monitoring System}

For the monitoring temperature system, we have developed the system using Arduino IDE microprocessor as shown in Figure 5. There are several components including the hardware software that have been considered in developing the sensor. This is shown in Table 1. 


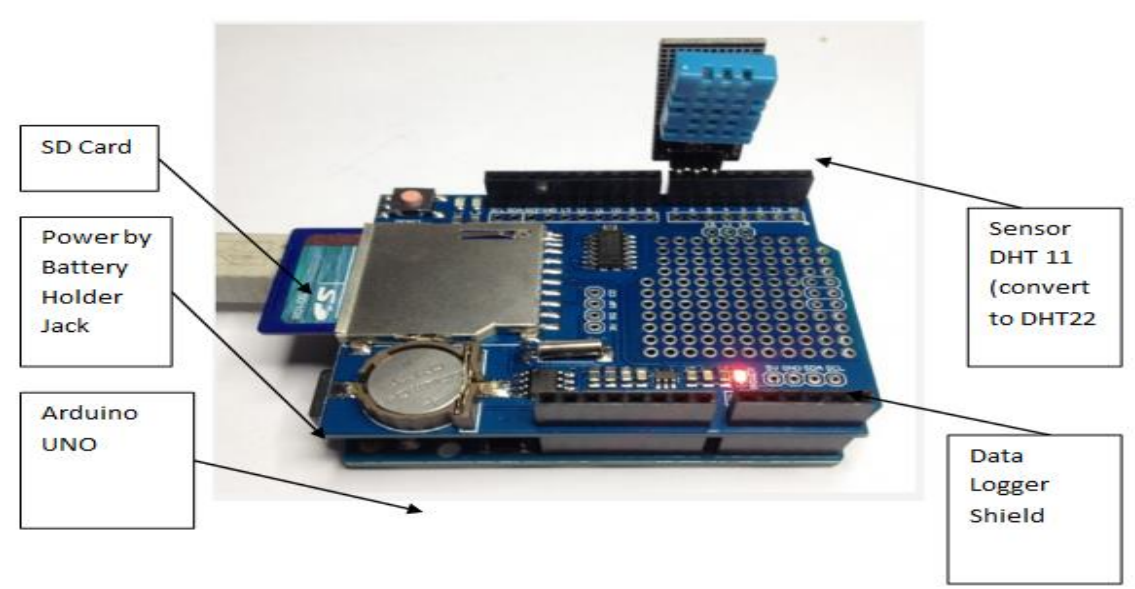

Figure 5. Propose Temperature Monitoring Device

Table 1. Key Hardware List

\begin{tabular}{|l|l|}
\hline Arduino Uno Starter & $\begin{array}{l}\text { RHT03/DHT-22 } \\
\text { Humidity and } \\
\text { Temperature } \\
\text { sensor }\end{array}$ \\
\hline $\begin{array}{l}\text { Dit } \\
\text { Data Recorder Data } \\
\text { Arduino UNO SD Card } \\
\text { with 3V CR1220 lithium } \\
\text { button cell }\end{array}$ & $\bullet$ microSD card \\
\hline
\end{tabular}

Among the key software used are namely Arduino IDE 1.0.5, Adafruit DHT sensor library as well as DS3234 RTC library

\section{Experimental Setup}

Figure 6 depicts the on-going experimental setup for collecting temperature data according to the direction of the sun. There are three house models where house with thin leaves tree (labelled as A), house with thick leaves tree (labelled as B) and house without any tree (labelled as $\mathrm{C}$ ). The house models are organized in such a way with direct exposure to the sun, from dusk till dawn, rising from the east and setting in the west. The trees are placed next to the house, blocking direct sunlight by providing shades to the houses. Shadow of the tree is one of the main factors that can cool the house. Past every noon each day, the tress are re-organised to provide covers for the houses from the west direction in order to keep the houses under shades. The trees are adjusted around $1 \mathrm{PM}-2 \mathrm{PM}$. Every day at 4 PM the data are collected and transferred using SD Card and processed using Microsoft Excel. The collected data were processed into graph format. 


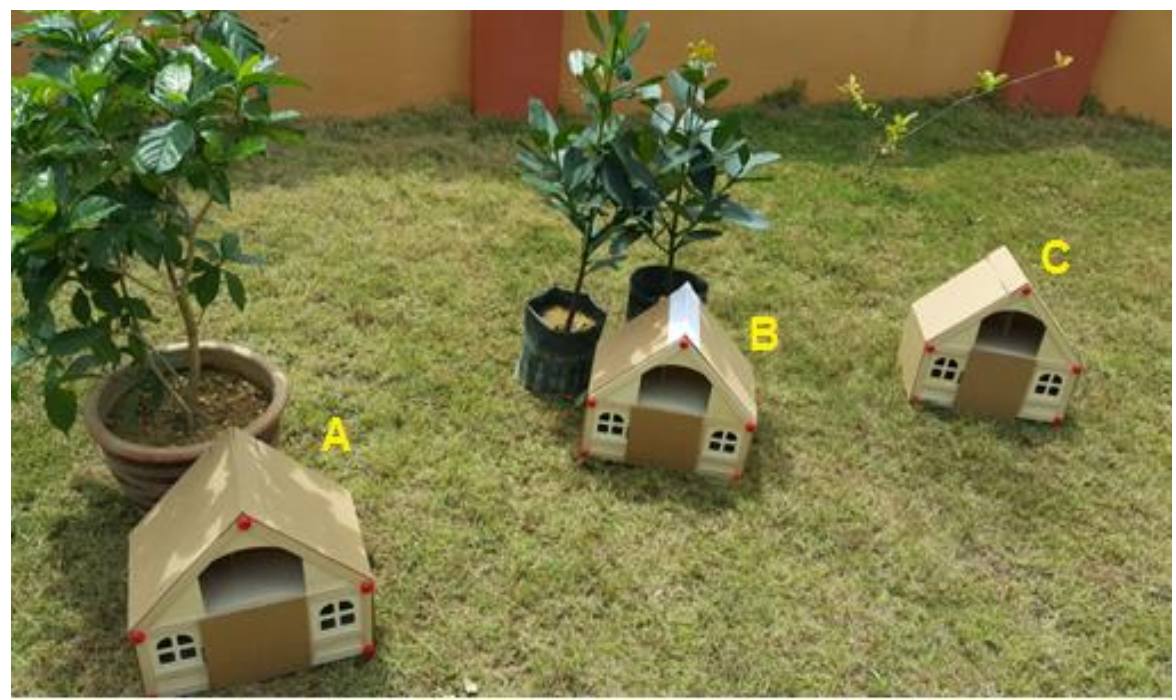

Figure 2. System Architecture for Modelling the Temperature Monitoring Studies

\section{Analysis of Results}

The results of these studies are shown in Figure 7 and 8, respectively. Both diagrams show that there is a decrease in temperature for the house model surrounded by thick plant. The difference on average is about 0.5-3 degree Celsius range.

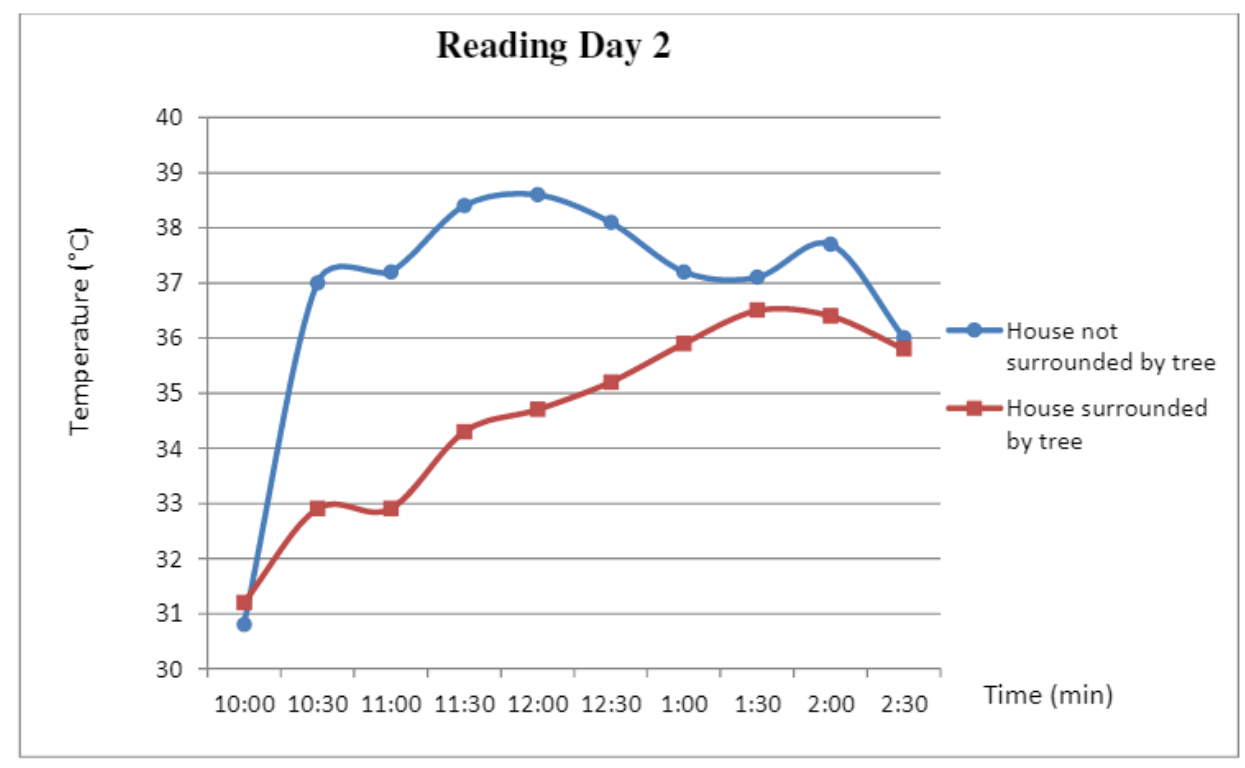

Figure 7. Temperature Performance for Indoor on Day 1 


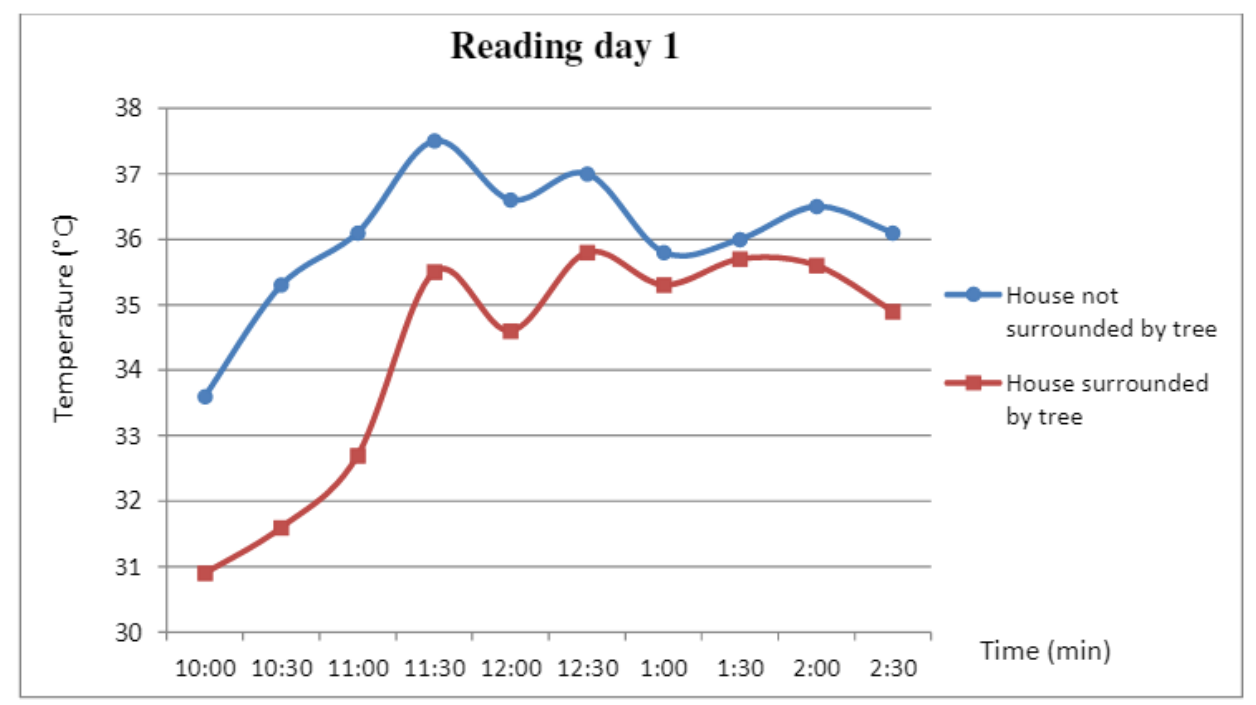

Figure 8. Temperature Performance for Indoor on Day 2

There is no temperature difference at certain time of data collection due to some programming initialization in the device. We have encountered several problems when data collection.

\section{Conclusion}

It can be concluded that there is a drop of temperature when such research project is conducted. The range of differences from 0.5-3 degree Celsius can be justified from the limited number of days since several days were raining. For future work, we opt for a longer period of data collection to enhance the accuracy of the decrement in temperature and also to observe the impact of leaves thickness to the reading. Since this is only preliminary studies, we shall extend the research into wider perspective and the energy efficiency is discussed here.

\section{Acknowledgements}

We would like to state our outmost gratitude to FRIM and UNITEN for the guidance in conducting this research work.

\section{References}

[1] T. Kubota, "Energy Consumption and Air-Conditioning Usage in Residential Building of Malaysia", vol. 17, (2011), pp. 61-69.

[2] N. Zainal, "Faculty of Resource Science and Technology: Diversity of urban trees in International college of advanced technology Sarawak", vol. 436, (2013), pp. 11-12.

[3] K. Doick and T. Hutchings, "Air temperature regulation by urban trees and green infrastructure", vol. 12, (2013), pp. 1-10.

[4] US Environmental Protection Agency, "Using Trees and Vegetation to Reduce Heat Islands", vol. 1, (2015), pp. 1-2.

[5] L. Osborn, "Summer Temperature Averages for Every State", vol. 1, (2015), pp. 1-2.

[6] World Travel Guide, "Malaysia Weather, climate and geography", vol. 1, (2016), pp. 1-2.

[7] UN Volunteers, "Sustainable Development Goals: information and guidance for volunteer organizations", vol. 2, (2016), pp. 1-9.

[8] A. Back, "Building a Connected Greenhouse", vol. 2, (2016), pp. 1-2.

[9] Prometec, "Data Logger Shield V1", vol. 1, (2016), pp. 1-2. 


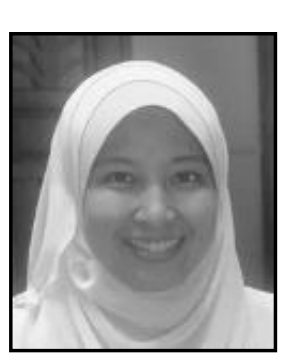

\section{Authors}

Wahidah Hashim, received her bachelor degree in Information Technology, Business Management and Language from University of York, UK in 1999. She then pursued her MSc in Multimedia Technology at University of Bath, UK in 2001. She completed her PhD studies from King's College London, UK in 2008 in the field of Telecommunication Engineering. She is currently at Universiti Tenaga Nasional, system and networking department, College of Computer Science and Information Technology as a principle lecturer since 2014. Prior to this, she was a staff researcher at MIMOS Berhad, a Malaysian National R\&D in ICT sector. Apart from her main task in doing research in cognitive radio, WLAN, OFDM, MIMO systems, IoT, Big Data and wireless system, she is actively involved in the development of Malaysia technical specification, standard and guidelines of wireless devices, International Mobile Telecommunication (IMT) systems and sensor network for Malaysian Communications and Multimedia Commission (MCMC). Dr. Wahidah has published several publications and filed several patents on her research findings. She is a member of the IEEE and IACSIT.

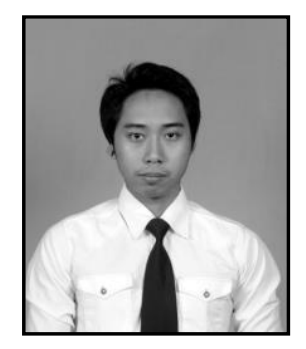

Amirul Haziq bin Ahmad, Amirul Haziq is a undergraduate student from the Universiti Tenaga Nasional (UNITEN) in Selangor, Malaysia. He received his Bachelor's degree from UNITEN in Computer Science (System and Networking). He is currently researching in Evaluation of Temperature Performance UsingEmpirical Eco-friendly Approach in Reducing Carbon Footprint and Energy. His area of interest in research is plant efficiency, embedded system, energy-saving technique and networking. 